\title{
FILOSOFÍA PRÁCTICA Y EDUCACIÓN MORAL: MÁS ALLÁ DE OBJETIVISMOS Y SUBJETIVISMOS MORALES
}

\section{PRACTICAL PHILOSOPHY AND MORAL EDUCATION: BEYOND OBJETIVISMS AND SUBJETISMS MORALS}

Ángel Gómez Navarro*

\begin{abstract}
RESUMEN
El presente escrito promueve una nueva educación moral que busca superar los objetivismos y subjetivismos morales y plantea la necesidad de formar la autonomía moral de la persona contrarrestando todo tipo de heteronomía moral en nuestra sociedad. Como referente teórico se parte de la filosofía moral de Kant así como de la visión educativa de uno de los padres de las ciencias sociales, Emile Durkheim, para terminar en la filosofía práctica de JürgenHabermas, analizando previamente la concepción del desarrollo moral propuesta por la psicología cognitivaevolutiva de Jean Piaget $y$ Lawrence Kohlberg.
\end{abstract}

\section{PALABRAS CLAVE:}

Autonomía moral, educación moral, subjetivismo, objetivismo, juicio moral

\begin{abstract}
The present paper promotes a new moral education that seeks to overcome the moral subjectivisms and objectivisms morals, and proposes the need to form the moral autonomy of the person counteracting all kinds of moral heteronomy in our society. As a theoretical reference, start point is the Kant's moral philosophy and educational vision of one of the fathers of the social sciences, Emile Durkheim, to end in the practical philosophy of Jürgen Habermas, previous analysis about conception of moral development proposed by the cognitive-evolutionary psychology of Jean Piaget and Lawrence Kohlberg.
\end{abstract}

\section{KEY WORDS:}

moral autonomy, moral education, subjectivism, objectivism, moral judgment

* Docente Principal de la Universidad Femenina del Sagrado Corazón: agomez@unife.edu.pe 


\section{INTRODUCCIÓN}

La educación tradicional concede el calificativo de persona con talante moral al hecho de cumplir externamente la obligatoriedad de las normas, y su correlato los valores, establecidos por la sociedad, sin tener lo suficientemente en cuenta ni la convicción interna ni la situación particular desde la que actúa el individuo. Este tipo de educación se preocupa exclusivamente por dar a conocer la estructura axiológica y normativa vigente con la finalidad de determinar la conducta moral de los niños y jóvenes de la sociedad. Aquí se presupone que los valores y los juicios morales que se derivan de aquellos pueden ser aprehendidos en virtud de una racionalidad que, independientemente de sentimientos y contextos particulares, les proporciona validez general. Sin embargo, tal preocupación devino en un objetivismo o deontologismo moral, es decir, en un moralismo alienante de la persona porque sólo enfatiza los datos de la razón y el cumplimiento formal externo de la norma por la norma, excluyendo todo tipo de contexto socioafectivo que, como sabemos, influyen en los juicios valorativos, en las decisiones y acciones morales,sobre todo cuando los sujetos buscan dar solución a los conflictos de valores que experimentan.

La reacción lógica ha sido la reivindicación del extremo opuesto; es decir, la afirmación de un subjetivismo o emotivismo moral, en donde la persona valora, decide y actúa sólo en función de sus intereses situacionales o según la sola intencionalidad al margen de toda objetividad normativa. Aquí, tanto los valores como las normas pierden objetividad y relevancia cognitiva, y más bien son reducidos a simples sentimientos o estados emocionales propios de las circunstancias pasajeras. Esta situación se agudiza al señalar que cuando hay que valorar, decidir y actuar, en modo inmediato, la razón práctica se experimenta como estrictamente limitada al no poder verificar todas las opciones que se le pueden presentar.

De esto se infiere que ni objetivismo (cognitivismo) ni subjetivismo (emotivismo) pueden patrocinar una educación moral autónoma de la persona. Desde la filosofía práctica se requiere más bien articular estas dos dimensiones de la moralidad en la construcción de las valoraciones o juicios morales mediante el desarrollo de aquellas capacidades socio-cognitivas y afectivas que son como las condiciones de posibilidad de un actuar moral responsable y un discernimiento ético auténtico.

\section{Kant y la Autonomía Moral}

La nueva educación moral que patrocinamos tiene, por un lado, su inspiración en las ideas de los filósofos alemanes Inmanuel Kant y Jürgen Habermas, y por otro lado, su desarrollo con base empírica en un grupo de psicólogos cognitivos como Jean Piaget y Lawrence Kohlberg, entre otros, a los que se suman las reflexiones de Emile Durkheim, quienes conciben la educación moral como el desarrollo de juicios morales sustentados en habilidades socio-cognitivas de la persona en su respectivo contexto histórico.

La preocupación de la filosofía práctica kantiana ha consistido en promover la autonomía moral del individuo, partiendo de serios cuestionamientos a la heteronomía moral aparentemente legitimadas por las concepciones aristotélicas e incluso aquellas cristianas. En su libro titulado "Fundamentación para una metafísica de las costumbres" 
(2003), Kant critica la heteronomía moral señalando que se trata de una conciencia que sólo actúa movida por los imperativos hipotéticos o condicionales, no por los categóricos. Es decir, se realiza una acción buena como medio para alcanzar algún fin o propósito considerado como bueno, posible o real, como la felicidad (Aristóteles) o la salvación eterna (Cristianismo), mientras que el imperativo categórico o imperativo de moralidad consiste en que la conciencia moral actúa lo bueno en sí, o sea, como aquello que es necesario en una voluntad conforme de suyo con la razón.

Así, el imperativo categórico no se refiere a ningún otro propósito y declara la acción como objetivamente necesaria de suyo, al margen de cualquier otro fin y que manda a un sujeto libre que puede o no obedecer. Este imperativo es único: "Obra sólo según aquella máxima por la cual puedas querer que al mismo tiempo se convierta en una ley universal" (Kant, 2003: 104).

Kant señala que la necesidad práctica de obrar según este principio, o sea, el deber, no descansa en sentimientos, impulsos e inclinaciones, sino simplemente en la relación de los seres racionales entre sí, donde la voluntad de un ser racional tiene que ser considerada siempre al mismo tiempo como legisladora, porque de lo contrario no podría pensarse como fin en sí mismo.

Para nuestro filósofo, la posibilidad de una autonomía moral está esencialmente en la posibilidad de una voluntad libre, y no como seres obligados por el mundo sensible. Sostiene que la moralidad autónoma nos libera de los mecanismos de la naturaleza en la medida que nos somete a leyes racionales dadas por nosotros mismos, y que él denomina leyes de la razón práctica.
Esta moral autónoma sólo es tal si procede por deber, es decir, por respeto a la ley moral autoimpuesta por la voluntad libre o buena voluntad. Esta ley moral se extiende más allá de los límites individuales del hombre, pues le exige considerarse parte de un reino de iguales, en el que cada uno tiene el deber de tratar a los demás como un fin en sí mismo. La máxima al respecto dice así "Obra de tal modo que uses a la humanidad, tanto en tu persona como en la persona de cualquier otro, siempre como un fin al mismo tiempo y nunca solamente como un medio".

Aquí Kant presenta el buen obrar autónomo como respeto a la ley moral interior y, al mismo tiempo, como acto de juicio cognitivo resuelve el problema de las inclinaciones, impulsos, sentimientos y emociones que son como mecanismos de la naturaleza. Sin embargo, no nos dice cómo se alcanza esta autonomía moral, qué dinamismo psíquico se activa, qué etapas deben seguirse y qué rol juega la intersubjetividad.

Teniendo en cuenta estas observaciones, Piaget y Kohlberg construirán sus teorías del desarrollo moral con el fin de dar una explicación sobre los procesos cognitivos, conativos e interactivos que configuran la autonomía moral. Sin embargo, presentamos a continuación las ideas en torno a la educación moral propuestas por el sociólogo Emile Durkheim, ya que su perspectiva, distinta y complementaria, presenta el rol relevante que juega el hecho social en la formación moral de los individuos, lo cual suscitó serias reacciones en Jean Piaget.

\section{La Educación Moral según Durkheim}

Durkheim (2002) concibe la educación moral como aquella que debe darse en la 
etapa escolar, y fundarse al mismo tiempo en una racionalidad científica y ser laica, es decir, debe estar desvinculada de cualquier tipo de religión revelada. Tal educación debe contribuir a la cohesión social y evitar cualquier tipo de anomia o debilitamiento de la estructura social, es decir, evitar la disfuncionalidad de las instituciones. Son tres sus elementos claves: el espíritu de disciplina, la vinculación a los grupos sociales y la autonomía de la voluntad.

Nuestro autor sostiene que la moral hace que el sujeto sea solidario con su grupo y unido a los demás, oponiéndose así a todo tipo de egoísmo que implica ruptura de los lazos solidarios. Por consiguiente, la solidaridad social se constituye en la base del orden moral. Él mismo dirá que la moral es un conjunto de prescripciones y prohibiciones, que tiene como función principal regularizar las conductas, operar como un molde o un patrón que garantice la homogeneidad de las respuestas de los individuos frente a situaciones similares. Sin embargo, considera que hay que ir más allá de la mera formación de hábitos de respuestas regulares, ya que la supresión de la arbitrariedad individual y la contingencia de las respuestas frente a contextos situacionales parecidos implica que colectivamente se considere a todo aquel que no respete los patrones regulares de conducta como alguien poco merecedor de confianza (Durkheim: 2002).

En esta perspectiva, y a diferencia de la propuesta kantiana, Durkheim considera que las normas morales no son prescritas por la racionalidad subjetiva o individual sino por la sociedad organizada, la cual obliga desde fuera a modo de fuerza exterior, mandato o imperativo. En la práctica los individuos se topan no con principios éticos universales sino con normas morales particulares cuya aceptación se produce porque va asociada al reconocimiento de que existe una autoridad que trasciende al individuo, siendo esta autoridad la propia sociedad, la cual es capaz de garantizar la regularidad de la moral en los individuos. De ahí la necesidad de un espíritu de disciplina o disposición que ayude a lograr la cooperación entre los individuos, moderar los deseos y alcanzar la felicidad, ya que la disciplina es el medio por el cual la naturaleza humana se realiza. Es por eso que toda sociedad construye sus propias normas morales que pretenden regular las relaciones entre los individuos, pues es la sociedad la que hace la moral y son los individuos los que deben someterse a ella; Durkheim (2002) dirá que "sólo somos seres morales en la medida que somos seres sociales".

En último término, exige de los educadores tenacidad para reprimir; porque la represión forma parte de los procesos desocialización imprescindibles y universalmente presentes. No hay sociedad sin normas, sin reglas de convivencia socialmente fijadas, y que es necesario respetar a riesgo de sufrir sanciones negativas. Hay que coactar externa e internamente para generar un sentimiento de obligatoriedad con respecto a la aceptación de las normas.

En suma, en Durkheim se puede apreciar una concepción de educación moral eminentemente adaptativa que legitima el factor social en relación al cumplimiento externo de las normas morales, sin embargo, su visión refuerza indirectamente la heteronomía moral porque el sujeto busca sólo responder a una dinámica de socialización de tipo conductista, pues su conducta moral no es más que una reacción a estímulos externos que se le imponen 
(bajo amenaza de castigo) sin que su conciencia y voluntad internas jueguen un rol más protagónico en la aceptación, rechazo o cuestionamiento de las normas sociales.

Así las cosas, podemos afirmar que si bien la presión social podría ser considerada como necesaria para la formación social, sin embargo no es suficiente para el desarrollo de las competencias morales que lleven a la autonomía moral de la persona en su contexto social y cultural específicos.

\section{La Educación Moral según la Psicología Cognitiva}

A diferencia de la perspectiva durkheimiana, la educación moral de la psicología cognitiva evolutiva de Piaget y Kohlberg le confiere primacía al juicio moral. Esta teoría implica el desarrollo que sigue algunas etapas, niveles o estadios evolutivos en los que el individuo al recorrerlos va alcanzando su madurez moral, en la medida que integra lo cognitivo con la interacción social y la experiencia de la reciprocidad (Rubio, 1996).

Con la publicación de su libro, "Las reglas del juego moral de los niños" (1932), Jean Piaget plantea la educación moral como el paso de la heteronomía moral a la autonomía, es decir, al respeto autónomo de las normas o reglas morales. Según él, la heteronomía moral es el primer estadio propio de los niños (6-8 años) porque, al poseer un pensamiento concreto, consideran las normas morales como externas e impuestas por la autoridad absoluta de los adultos. Luego, en la medida que el desarrollo cognitivo permite nuevas adquisiciones lógicas (8-11 años) se da un nuevo avance en donde estas normas o reglas morales de adultos se transforman paulatinamente al darse relaciones de igualdad, de lo cual surge el estadio convencional en donde las normas son el resultado del acuerdo y la cooperación entre iguales. El último estadio (a partir de los 12 años) es la etapa en que el desarrollo cognitivo, que ha permitido que el pensamiento realice inferencias lógicas, inductivas y deductivas, se configura progresivamente en equidad y justicia racional. Aquí se puede observar la superación de la aplicación rígida y heterónoma de la norma y la consideración individual de la propia conducta, lo que implica la adquisición de habilidades para formular principios morales generales y al mismo tiempo afirmarse de manera autónoma frente a las normas exteriores.

Respecto a la omisión intencional de las diferencias individuales y de las emociones se ha dicho que "a Piaget no le interesan las diferencias individuales en vista que su investigación se enfocaba en cómo el ser humano en general adquiere, procesa u olvida el conocimiento; de igual forma, prescinde voluntariamente de contenidos emocionales en su teoría debido a que se interesó más en el estudio del desarrollo de los procesos y funciones mentales" (Zerpa, 2007).

Piaget se preocupó por configurar el desarrollo del juicio moral en los niños siguiendo una metodología donde combinó observación, entrevistas y análisis interpretativo en una muestra de niños de escuelas de Ginebra. La primera parte de su investigación giró en torno al respeto que el niño tiene por las reglas del juego de las canicas. La segunda estudia la mentira en relación a las pautas morales establecidas por los adultos. Y la última parte trata sobre la noción de justicia que surgen en las relaciones entre adultos y niños y en los niños entre sí. 
Aunque Piaget considera que el desarrollo de la moralidad es paralelo a la evolución del pensamiento lógico, sin embargo, no pudo caracterizar adecuadamente los estadios de su desarrollo moral, pero quien al parecer sí alcanzó este objetivo fue Lawrence Kohlberg a partir de una metodología basada en dilemas morales o de conflicto de valores, cuidadosamente aplicados e interpretados y que desembocó en la presentación de los siguientes tres niveles evolutivos superiores, cada uno con sus dos respectivos estadios:

\section{NIVEL PRECONVENCIONAL}

Este nivel se corresponde con la etapa egocéntrica de Piaget donde las reglas morales mantienen un carácter externo al yo y responden a imperativos hipotéticos con razonamientos que buscan obtener un premio o evitar un castigo. En este nivel encontramos a niños menores de 9 años

\section{Estadio 1: Estadio de castigo y obediencia}

El niño busca evitar la trasgresión a las normas por miedo al castigo y porque así lo exige la autoridad. Estamos ante una perspectiva egocéntrica, donde el niño no considera los intereses de los demás ni reconoce que los intereses de otros difieren de los propios. Se somete a la autoridad y considera las consecuencias físicas de la acción, sin tener en cuenta la intención.

\section{Estadio 2: Estadio de intercambio individual instrumental}

El niño considera que hay que seguir las normas cuando responden al interés propio reconociendo que otras personas también tienen sus intereses. Aquí la perspectiva es individualista concreta, pues hay la conciencia de que todos persiguen sus propios intereses y la acción correcta a seguir, por tanto, es satisfacer las propias necesidades y ocasionalmente las de los otros, pero desde un punto de vista concreto y pragmático (si hago algo por el otro, él también lo hará por mí).

\section{NIVEL CONVENCIONAL}

En este nivel se encuentran la mayoría de los adolescentes, aunque, según Kohlberg, muchos adultos no logran superar este nivel. El adolescente se enfrenta a los dilemas morales desde la perspectiva de miembro de la sociedad y argumenta en favor de lo que es bueno para la sociedad en su conjunto. Aquí el grupo está por encima del punto de vista individual.

\section{Estadio 3: Estadio de expectativas, relaciones y conformidad mutuas interpersonales}

Se debe ser una buena persona (leal, respetable, colaborador), a los propios ojos y a los de los demás. La buena conducta es la que agrada o ayuda a los otros y es aprobada por ellos. Es una perspectiva del individuo en relaciones con otros individuos. Se sigue fielmente la regla de oro ("no hagas a otro lo que no quieras que te haga a ti o haz lo que quieras que los demás hagan contigo"). Se trata de una perspectiva social que permite considerar los sentimientos, acuerdos y expectativas comunes que prevalecen sobre los intereses personales.

\section{Estadio 4: Estadio del mantenimiento del sistema social y de conciencia}

Hay que cumplir los deberes y acuerdos que uno ha aceptado, y 
contribuir a la sociedad, al grupo o la institución con la finalidad de mantener el orden establecido y evitar la descomposición de un sistema institucional o social. La perspectiva consiste en tomar el punto de vista del orden social que define roles y normas y considera las relaciones individuales en términos del lugar en el sistema social.

\section{NIVEL POSTCONVENCIONAL}

Es la culminación del desarrollo evolutivo y acceden a él los adultos mayores de veinte años. Aquí el razonamiento moral maduro diferencia claramente el yo de las normas morales y expectativas de los otros y define sus valores en atención a principios elegidos libremente.

\section{Estadio 5: Estadios de derechos prioritarios y contrato social}

Se tiene conciencia de que la gente posee una variedad de valores y opiniones, que la mayoría de valores, normas o reglas son relativos al propio grupo. Pero reconoce que hay valores, como la vida y la libertad, que han de ser defendidos en cualquier grupo o sociedad sin considerar la opinión mayoritaria. En este estadio hay una perspectiva de un individuo racional consciente de los valores y los derechos previos a las vinculaciones y los contratos sociales. Integra perspectivas mediante mecanismos formales de acuerdo, contrato, imparcialidad objetiva y debido proceso. Considera los puntos de vista moral y legal; reconoce que a veces están en conflicto y le resulta difícil integrarlos.

\section{Estadio 6: Estadio de principios éticos universales}

En este último estadio se sigue los principios éticos elegidos libremente. Las leyes y los acuerdos son válidos sólo si basan en tales principios. Cuando una ley viola los principios universales la persona razona según tales principios como el de justicia que incluye la igualdad de los derechos humanos y el respeto por la dignidad de los seres humanos como personas individuales. Aquí la persona manifiesta un sentido de compromiso personal con los principios universales. Estamos ante la perspectiva de un punto de vista moral del cual derivan los arreglos sociales. La perspectiva es de cualquier individuo racional que reconoce la naturaleza de la moralidad o el hecho de que las personas son fines en sí mismas y deben ser tratadas como tal.

El recorrido de los estadios implica seguir una secuencia lógica o evolutiva del desarrollo moral, donde cada estadio, con base empírica y disposición jerárquica, es concebido como una "totalidad estructurada" y en el que se activa un proceso lógico, especialmente cuando los valores adquiridos entran en conflicto formándose de este modo el juicio moral estrechamente vinculado al valor o principio de la justicia. Es decir, ante una situación que confronta a dos valores (dilema moral), se produce un desequilibro cognitivo; luego, el equilibrio perdido debe restaurarse asimilando el problema o acomodándose el pensamiento para abordar la crisis e idear cómo resolver el conflicto identificado entre tales valores. El mismo Kohlberg dirá sobre sus estadios lo siguiente:

Hemos presentado evidencias de una secuencia moral invariante, culturalmente universal así como evidencias de que esta secuencia representa una jerarquía acumulativa de complejidad cognitiva, percibida como sucesivamente más adecuada 
por los sujetos que no son filósofos. Luego bosquejamos la estructura lógica de cada estadio, al mostrar el modo en que cada estadio más alto (a) tenía nuevos rasgos lógicos, (b) incorporaba los rasgos lógicos de los estadios más bajos, y (c) daba dirección a los problemas no reconocidos, o irresueltos, por los estadios más bajos. Hemos intentado mostrar que una estructura de justicia, que organiza modelos para la asunción de roles en situaciones morales conflictivas, constituye el núcleo común en todos los estadios, para culminar en el estadio 6 con la capacidad de derivar consistentemente decisiones morales del principio generalizado de justicia; esto significa, usarlo como una guía consistente para la asunción de roles en las distintas situaciones, independientemente de las especificaciones arbitrarias del orden particular del juez moral. Estas ideas bosquejan nuestra teoría psicológica del juicio moral, una teoría que asume ciertos postulados filosóficos en consideración de la explicación psicológica" (Kohlberg, 1998: 205-206).

\section{Desarrollo moral y ética discursiva según Jürgen Habermas}

Habermas considera que la teoría del desarrollo moral presentada por Kohlberg es la estructura básica para una ética racional y universalista; es decir, reconoce que los fundamentos psicológicos de la moralidad de cualquier juicio o norma de acción moral se complementa con sus interpretaciones filosóficas de la ética o filosofía práctica. Sin embargo, sostiene que el estadio 6 del nivel postconvencional, legitima una racionalidad monológica o individualista, al estilo kantiano, en el que se desconoce a la racionalidad dialógica, discursiva o intersubjetiva. En dicho estadio los conflictos morales se resuelven apelando a la esfera interna del sujeto que vislumbra monológicamente aquellos principios morales universales. Para Habermas, el estadio moral más elevado debe incluir el diálogo real entre iguales con el propósito de lograr los consensos validados intersubjetivamente sobre aquellos principios morales aplicados en situaciones similares. De esta manera se logra superar la brecha entre la pura universalidad y su aplicación a las circunstancias concretas de la vida. Él mismo dirá que "el discurso práctico se puede concebir como un proceso de entendimiento que, por su forma, esto es, partiendo de las presuposiciones generales e inevitables de la argumentación, exhorta a todos los interesados a la adopción ideal de rol. Transforma la adopción ideal privada y particular de Kohlberg en una pública, en la idea de la organización practicada en común por todos (los afectados)" (Citado por Gonzálvez, 2000:247).

Todo esto significa que alcanzar el nivel postconvencional o de madurez moral no es el fruto de un desarrollo natural (biológico) sino de una propuesta éticamente y racionalmente deseable en la medida que se construya en modo intersubjetivo. En este sentido, Habermas reformula el estadio final del desarrollo moral kohlberiano yendo más allá de las razones psicológicas, es decir, recurriendo a las razones éticofilosóficas tanto para fundamentar como para afianzar dicho estadio. "El nuevo estadio 6 no tiene valor como estadio empíricamente registrado, pero sí como pauta ético-normativa de un desarrollo moral maduro y, para ello, es preciso apelar tanto a argumentos filosóficos como a exigencias de coherencia en la lógica interna misma del desarrollo (Gonzálvez, 2000:249).

Las implicancias para la educación moral son muy ricas, pues la interacción 
dialógica es un óptimo motor pedagógico para una moralidad madura que se puede estructurar institucionalmente en aquellas comunidades educativas que buscan ser democráticas, participativas, igualitarias, dialógicas, etc.

\section{Lind y los dilemas morales en la educación moral}

La importancia de los dilemas morales en la educación moral ha sido defendida también por Georg Lind (2007), quien al mismo tiempo ha subrayado el componente afectivo en la construcción del juicio moral, el cual complementa al aspecto cognitivo; de ahí que su aporte haya sido denominado como teoría del aspecto dual (Zerpa 2007), es decir, cognitivo-afectivo o método de Konstanz, que tiene como propósito desarrollar las competencias morales y orientar en la resolución de conflictos morales mediante la argumentación y contra argumentación, lo que supone también habilidades comunicativas y dialógicas teniendo en cuenta los principios éticos supriores y universales. En efecto, una cosa es reconocer los valores, principios y normas morales y otra el modo cómo se aplican u orientan en cada situación particular de la vida pública y privada del individuo y su comunidad.

Las decisiones y acciones morales que asumimos no sólo tienen que ver con nuestra capacidad cognitiva sino también con nuestra capacidad afectiva, o sea, con nuestras emociones y experiencias, así como con el medio social en que nos desenvolvemos e interactuamos. Es lo que Lind llama nuestro ADN interpretativo que nos ayuda a construir criterios para elaborar las mejores decisiones en las resoluciones de los conflictos morales que se nos presentan constantemente. Estos dilemas morales ayudan a:
- Articular los propios sentimientos y emociones ligados a conflictos

- Atreverse a hablar aun en casos de ansiedad y en circunstancias hostiles

- Distinguir entre la calidad de opiniones (sean o no contrarias a mis propias opiniones)

- Reconocer conflictos, valores morales y otros valores

- Diferenciar los dilemas de conflictos entre personas

- Diferenciar problemas de valores de problemas técnicos

- Diferenciar principios morales de valores humanos no universalizables

- Utilizar la razón para resolver conflictos

- Utilizar el diálogo con otras personas para resolver conflictos

- Apreciar el valor de oponer razonamiento a crítica para el propio desarrollo

- Apreciar el discurso racional con oponentes para mantener y desarrollar el orden social.

\section{CONCLUSIÓN:}

Los desafíos de la nueva educación moral giran en torno a cómo se articulan la dimensión cognitiva con la dimensión social y afectiva al momento de construir los respectivos juicios morales, buscando ir más allá de los modelos objetivistas y subjetivistas, es decir, de lo meramente externalista y sociologista que no hacen más que reforzar la heteronomía moral. Asimismo, se requiere superar toda forma de relativismo axiológico que sumerge a la persona en la irracionalidad subjetivista, encerrándola en sí misma y legitimando los diversos modos de sentimentalismo moral.

Esta nueva educación moral no puede reducirse a enseñar códigos morales preestablecidos o presionar para su respectiva aplicación mecánica. Muy por 
el contrario, debe promover aquellas competencias que apuntan a formar con sentido crítico y libertad responsable una autonomía moral y en clave relacional, ya que los juicios morales no se imponen sino que se construyen intersubjetivamente en relación a los valores objetivos y la búsqueda de soluciones a los dilemas morales que se nos presentan en el día a día.

Hay que evitar el riesgo de una educación moral exclusivamente individual, es decir, una moral atomista que termina concibiendo al ser humano como un ser ensimismado con intereses, propósitos y necesidades que poco o nada tienen que ver con el deseo, intereses, propósitos y necesidades de los demás. Necesitamos formar una autonomía moral abierta a los valores y principios comunitarios y democráticos que mueven a la persona a mirar más allá de sus fronteras y articular sus intereses con los del bien común.

Una auténtica moral autónoma sólo será posible desde una ética de la corresponsabilidad, la cual se configura desde una interacción dialógica que pone a la persona junto a otras, en clave intersubjetiva y diálogo democrático. Se trata de una autonomía moral solidaria, donde los hombres son reconocidos y se reconocen como seres dignos y libres a través de la decisión y acción humana (Sepúlveda: 2003).

\section{REFERENCIAS:}

CAEIRO, M. (2002) Formación ética. Debate e implementación en la escuela. Buenos Aires: Santillana.
CORTINA, A. (2010) Ética sin moral. Madrid: Tecnos.

DELVAL, J. y ENESCO, I. (1998) Moral, desarrollo y educación. (3a Ed.) Madrid: Anaya.

DEWEY, J. (2008) Teoría de la valoración: un debate con el positivismo sobre la dicotomía de hechos y valores. Madrid: Biblioteca Nueva.

DURKHEIM, Emile (2002) La educación moral. Madrid: Morata.

GONZALVEZ, V. (2000) Inteligencia moral. Bilbao: Desclée De Brouwer.

HABERMAS, J. (1985) Conciencia moral y acción comunicativa. Barcelona: Península.

KANT, I. (2003) Fundamentación para una metafísica de las costumbres. Madrid: Alianza Editorial.

KOHLBERG, L. (1975) "El enfogue cognitivo-evolutivo de la educación moral". En Jordán, j. y Santolaria, F. (Eds.) La educación moral hoy. Cuestiones y perspectivas. Barcelona: PPU, 1987, pp. 85-114)

KOHLBERG, L. (1998) De lo que es a lo que debe ser. Cómo cometer la falacia naturalista $y$ vencerla en el estudio del desarrollo moral. Buenos Aires: Almagesto.

LIND, G. (2007) La moral puede enseñarse: manual teórico-práctico de la formación moral y democrática. México: Trillas.

LIND, G. (2011) "Promoviendo las competencias morales $y$ democráticas: 
expresarse y escuchar a otros". Revista Posconvencionales $n^{\circ} 3$. Caracas: Universidad Central de Venezuela. Pág. 26-41.

PUIG, J. y MARTINEZ, M. (1999) Educación moral y democracia. Barcelona: Laertes.

RUBIO, J. (1996) Educación moral, postmodernidad y democracia. Más allá del liberalismo y del comunitarismo. Madrid: Trotta.

SALMERON, A. (2000) La herencia de Aristóteles y Kant en la educación moral. Bilbao: Desclée De Brouwer.
SEPÚLVEDA, M. (2003) "Autonomía moral: una posibilidad para el desarrollo humano desde la ética de la responsabilidad solidaria". Revista de Psicología de la Universidad de Chile, Vol. XII, $\mathrm{n}^{\circ} 1$, Pág. 27-35.

ZERPA, C. (2007) "Tres teorías del desarrollo del juicio moral: Kohlberg, Rest, Lind. Implicaciones para la formación moral". Revista de Educación Laurus, Vol. XIII, n 023. Caracas: Universidad Pedagógica Experimental de Venezuela, Pág. 137-157. 